\title{
(C) OPEN ACCESS \\ An Asian consensus on standards of diagnostic upper endoscopy for neoplasia
}

\author{
Philip Wai Yan Chiu, ${ }^{\oplus 1}$ Noriya Uedo, ${ }^{2}$ Rajvinder Singh, ${ }^{3}$ Takuji Gotoda, ${ }^{4}$ \\ Enders Kwok Wai Ng, ${ }^{1}$ Kenshi Yao, ${ }^{5}$ Tiing Leong Ang, ${ }^{6}$ Shiaw Hooi Ho, \\ Daisuke Kikuchi, ${ }^{8}$ Fang Yao, ${ }^{9}$ Rapat Pittayanon, ${ }^{10}$ Kenichi Goda, ${ }^{11}$ James Y W Lau, ${ }^{1}$ \\ Hisao Tajiri, ${ }^{12}$ Haruhiro Inoue ${ }^{13}$
}

- Additional material is published online only. To view please visit the journal online (http://dx.doi.org/10.1136/ gutjnl-2018-317111).

For numbered affiliations see end of article.

\section{Correspondence to}

Professor Philip Wai Yan Chiu, Department of Surgery, The Chinese University of Hong Kong, Hong Kong; philipchiu@surgery.cuhk.edu.hk

Received 11 August 2018 Revised 25 September 2018 Accepted 15 October 2018

\begin{abstract}
Background This is a consensus developed by a group of expert endoscopists aiming to standardise the preparation, process and endoscopic procedural steps for diagnosis of early upper gastrointestinal (GI) cancers. Method The Delphi method was used to develop consensus statements through identification of clinical questions on diagnostic endoscopy. Three consensus meetings were conducted to consolidate the statements and voting. We conducted a systematic literature search on evidence for each statement. The statements were presented in the second consensus meeting and revised according to comments. The final voting was conducted at the third consensus meeting on the level of evidence and agreement.

Results Risk stratification should be conducted before endoscopy and high risk endoscopic findings should raise an index of suspicion. The presence of premalignant mucosal changes should be documented and use of sedation is recommended to enhance detection of superficial upper GI neoplasms. The use of antispasmodics and mucolytics enhanced visualisation of the upper GI tract, and systematic endoscopic mapping should be conducted to improve detection. Sufficient examination time and structured training on diagnosis improves detection. Image enhanced endoscopy in addition to white light imaging improves detection of superficial upper GI cancer. Magnifying endoscopy with narrow-band imaging is recommended for characterisation of upper Gl superficial neoplasms. Endoscopic characterisation can avoid unnecessary biopsy.

Conclusion This consensus provides guidance for the performance of endoscopic diagnosis and characterisation for early gastric and oesophageal neoplasia based on the evidence. This will enhance the quality of endoscopic diagnosis and improve detection of early upper $\mathrm{GI}$ cancers.
\end{abstract}

\section{INTRODUCTION}

Upper gastrointestinal (GI) cancers are common cause of cancer death worldwide. The prognosis of upper GI cancers is closely related to the stage of the disease. Generally, the 5 year survival rate for patients with early upper GI cancers exceeds $85 \%$. Patients with early stage upper GI cancers are usually asymptomatic. Endoscopic recognition can be difficult and is a major challenge to clinicians. Currently, there is no global consensus on the use of diagnostic upper endoscopy to recognise and characterise early GI cancers, especially from Asia where upper GI cancers are highly prevalent (approximately three quarters of the worldwide prevalence). ${ }^{12}$ In this paper, , we develop an Asian consensus regarding the preparation and application of image enhanced endoscopy (IEE) for the diagnosis of early upper GI cancers.

\section{METHODOLOGY}

A professional group was formed by leading Asian endoscopists as a non-government organisation to improve endoscopic diagnosis of early GI cancers through a structured educational programme in Asia. The group organised three meetings to develop a consensus on diagnostic endoscopy for GI neoplasia. The Delphi method was used to develop the consensus statements. The panel of experts was divided into two groups, focusing on upper and lower GI endoscopy, respectively. The upper GI statements are reported here.

First consensus meeting (22-24 January 2016)

The first face to face meeting focused on the drafting of consensus statements on standards of diagnostic upper GI endoscopy in the following areas:

1. Standard preparation for diagnostic endoscopy

2. Endoscopic recognition of early GI neoplasia

3. Endoscopic characterisation of early GI neoplasia.

Initial draft statements were formulated, discussed and agreed by the panel of experts. Each member was assigned to search for evidence for or against the respective statement and to prepare for discussion and voting in the following consensus meetings. The literature search for each statement was conducted on publications in English from scientific databases, including AMED, BIOSIS previews, EBM reviews, Embase, Ovid MEDLINE and Cochrane Trials and systematic reviews.

\section{PICO method for establishment of statements}

The PICO method (Problem/Population; Intervention; Comparison; Outcome) was employed to identify the appropriate intervention and standards for the conduct of diagnostic endoscopy, focusing on the detection and characterisation of early GI neoplasia as a clinical outcome. All statements were established following the PICO worksheet (figure 1) (see online supplementary 1).
To cite: Chiu PWY, Uedo $\mathrm{N}_{\text {, }}$ Singh $\mathrm{R}$, et al. Gut

2019:68:186-197. 
PICO Worksheet and Search Strategy

Name

1. Define your question using PICO by identifying: Problem, Intervention, Comparison

Group and Outcomes.

Your question should be used to help establish your search strategy.

\begin{tabular}{|l|l|}
\hline Patient/Problem & \\
\hline Intervention & \\
\hline Comparison & \\
\hline Outcome & \\
\hline
\end{tabular}

Write out the Statement:

2. Type of question/problem: Circle one:

Therapy/Prevention Diagnosis Aetiology Prognosis

3. Type of study (Publication Type) to include in the search: Check all that apply:

๑ Meta-Analysis ם Systematic Review a Randomised Controlled Trial

๑ Cohort Study a Case Control Study a Case series or Case Report

口 Editorials, Letters, Opinions a Animal Research $\square$ In Vitro/Lab Research

4. List main topics and alternate terms from your PICO question that can be used for your search

List your inclusion criteria - gender, age, year of publication, language

List irrelevant terms that you may want to exclude in your search

5. List where you plan to search, i.e. EBM Reviews, Medline, AIDSLINE, CINAHL, PubMede

Figure 1 PICO (Problem/Population; Intervention; Comparison; Outcome) worksheet and search strategy.

\section{Second consensus meeting (June 2016)}

After the search for evidence in respect of each statement, a second face to face meeting was conducted to refine the statements and to vote on them. Appropriate time was provided to members to refine each statement through discussion. After the meeting, a period of 5 months was allocated for the further collection of comments through a closed group internet platform.

\section{Third consensus meeting (November 2016)}

All the experts in the panel joined the third consensus face to face meeting and completed anonymous voting on all the statements.

\section{Delphi method for voting}

The expert panel formulated statements in two separate rounds of voting and opinion collection. After each round, facilitators provided a summary of the experts' opinions from the previous round for refinement. The voting was based on a review of the literature on a Likert scale which ranged from 1 to 5 (1=acceptcompletely, 2 =accept with some reservation, $3=$ acceptwith major reservation, $4=$ rejectwith reservation, $5=$ reject completely). All votes were cast anonymously by means of a wireless polling system. Consensus was achieved when $>80 \%$ of members indicated that they accepted the statement completely or accepted it with some reservation. If consensus was not reached, panel members discussed the statement again with a view to its modification. Discussion was followed by a second round of voting. If consensus was still not reached, the statement was discussed and modified for a third time and a final round of voting was conducted. Each statement was graded on the level of evidence in its support and the strength of the recommendation it received (tables 1, 2 and 3).

\section{CONSENSUS STATEMENTS}

Statement 1.1: Risk stratification regarding UGI cancers should be performed before diagnostic oesophagogastroduodenoscopy (OGD)

Level of evidence: III

Level of recommendation: $B$

Level of acceptance: $100 \%$

Identification of high-risk patients should alert the endoscopist to observe mucosa with greater care with more liberal application of IEE. There should be a lower threshold to biopsy suspicious lesions. ${ }^{3}$ There are individuals at higher risk of UGI cancer. Risk stratification performed before diagnostic oesophagogastroduodenoscopy (OGD) may improve cancer detection (table 4).

Oesophageal squamous cell carcinoma (SCC)

Oesophageal cancer is often diagnosed in patients aged $\geq 50$ years old. Smokers have a fivefold greater risk than

Table 1 Quality of evidence summarised for each of the statements will be graded according to the classification below

\begin{tabular}{ll}
\hline Level of evidence & \\
\hline $\mathrm{I}$ & $\begin{array}{l}\text { Evidence obtained from at least one randomised controlled } \\
\text { trial (RCT) }\end{array}$ \\
$\mathrm{HI}-1$ & $\begin{array}{l}\text { Evidence obtained from well-designed controlled trials } \\
\text { without randomisation }\end{array}$ \\
$\mathrm{II-2}$ & $\begin{array}{l}\text { Evidence obtained from well-designed cohort or case-control } \\
\text { study }\end{array}$ \\
$\mathrm{HI}-3$ & $\begin{array}{l}\text { Evidence obtained from comparison between time or places } \\
\text { with or without intervention } \\
\text { Opinion of respected authorities, based on clinical } \\
\text { experience and expert committees }\end{array}$ \\
\hline
\end{tabular}




\begin{tabular}{ll}
\hline Table 2 & Classification of recommendation \\
\hline Class & Statement \\
\hline A & There is good evidence to support the statement \\
B & $\begin{array}{l}\text { There is fair evidence to support the statement } \\
\text { C }\end{array}$ \\
$\begin{array}{l}\text { There is poor evidence to support the statement but } \\
\text { recommendation made on other grounds }\end{array}$ \\
D & $\begin{array}{l}\text { There is fair evidence to refute the statement } \\
\text { E }\end{array}$ \\
\hline
\end{tabular}

non-smokers. ${ }^{4}$ Alcohol consumption is a consistent risk factor for oesophageal SCC, and risk increases with the amount of alcohol consumed. About 40\% of East Asians experience 'facial flushing' after drinking alcohol, due to an aldehyde dehydrogenase 2 (ALDH2) deficiency. ${ }^{5} 6$ This is associated with a significant increased risk of oesophageal SCC compared with a fully active ALDH2 metaboliser for light, moderate and heavy alcohol drinking (ORs of 6.11, 53.86 and 77.10, respectively). ${ }^{7}$ Past history and/or concomitant SCC in the head and neck region or another part of the oesophagus increase the likelihood of oesophageal SCC. ${ }^{89}$

\section{Oesophageal adenocarcinoma}

The incidence of oesophageal adenocarcinoma is eight times higher in Caucasian men than in women. ${ }^{10}$ The risk of developing oesophageal adenocarcinoma is about twofold higher among smokers. ${ }^{1112}$ Currently there is no conclusive association of obesity with adenocarcinoma.

\section{Gastric adenocarcinoma}

The incidence of gastric cancer increases among patients aged $\geq 50$, with men having a twofold higher incidence. Worldwide, gastric cancer is more common in individuals with an East Asian, South and East European or Central and South American ethnic background. ${ }^{12}$ The occurrence of gastric cancer is 1.5-10.1 times higher in the siblings or offspring of gastric cancer patients. ${ }^{13}$ Several inherited cancer predisposition syndromes, including hereditary diffuse gastric cancer, familial adenomatous polyposis and Lynch syndrome, should be managed by experts in genetic testing and counselling.

Chronic Helicobacter pylori infection of the gastric mucosa causes inflammation followed by atrophy and intestinal metaplasia (IM), leading to dysplasia and cancer. ${ }^{14}$ Gastric cancer develops in about $1 \%$ of individuals with $H$. pylori infection, and $>95 \%$ of patients with gastric cancer have active or past $H$. pylori infection. ${ }^{15}$ Thus, past or current $H$. pylori infection, especially when combined with the presence of mucosal atrophy and/ or IM, is a substantial risk factor. ${ }^{16}$ In patients with a history of endoscopic resection of early gastric cancer (EGC), metachronous gastric cancer develops frequently, with a cumulative 5 year incidence of $7-15 \%$. H. pylori eradication reduces the risk of the development of metachronous gastric cancer, but never eliminates it. ${ }^{17} 18$

\section{Statement 1.2: Presence of endoscopic high-risk findings for UGI cancers should raise the index of suspicion of the endoscopists}

Level of evidence: III

Level of recommendation: $B$

Level of acceptance: 100\%

In addition to clinical information, important endoscopic findings are also associated with a significant risk of upper GI cancers. Therefore, endoscopists should be alerted to such findings during OGD (table 4).

\section{Oesophageal SCC}

Oesophageal melanosis is associated with oesophageal (OR 6.5, 95\% CI 2.9 to 15 ) and oropharyngo-laryngeal (OR 15, 95\% CI 4.1 to 53 ) SCC $^{19}$ (figure 2A). Iodine chromoendoscopy visualises precancerous dysplastic lesions in the oesophageal mucosa as Lugol-voiding lesions (LVLs, figure 2B). Patients with numerous ( $>10$ in an endoscopic image) LVLs $(\geq 5 \mathrm{~mm}$ ) have concomitant oesophageal SCC (OR 21, 95\% CI 11 to 43$),{ }^{20}$ and subsequent development of metachronous oesophageal SCC after

\begin{tabular}{|c|c|c|c|c|}
\hline & Statements & $\begin{array}{l}\text { Level of } \\
\text { evidence }\end{array}$ & $\begin{array}{l}\text { Level of } \\
\text { recommendation }\end{array}$ & $\begin{array}{l}\% \text { of } \\
\text { agreement }\end{array}$ \\
\hline 1.2 & Presence of endoscopic high-risk findings for UGI cancers should raise the index of suspicion of the endoscopists & III & B & $100 \%$ \\
\hline 2 & Presence or absence of premalignant mucosal changes during OGD should be documented & III & C & $100 \%$ \\
\hline 3.2 & $\begin{array}{l}\text { Use of an antispasmodic agent is recommended to enhance the detection rate of OGD and image enhanced } \\
\text { endoscopy (IEE) }\end{array}$ & III & C & $80 \%$ \\
\hline 3.3 & Use of mucolytic and/or defoaming agents is recommended for the improvement of visual clarity of OGD and IEE & I & A & $100 \%$ \\
\hline 4 & $\begin{array}{l}\text { Systematic endoscopic mapping of the entire oesophagus and stomach may improve the detection rate of UGI } \\
\text { superficial neoplasm }\end{array}$ & III & C & $100 \%$ \\
\hline 5 & Sufficient examination time is recommended to increase the detection rate of UGI superficial neoplasia & II & B & $89 \%$ \\
\hline 8 & IEE in addition to WLI is useful for the delineation of UGI superficial neoplasia & II-2 & B & $97 \%$ \\
\hline 9 & $\begin{array}{l}\text { Magnifying endoscopy with narrow band imaging (NBI) is recommended for better characterisation of UGI } \\
\text { superficial neoplasia }\end{array}$ & I & A & $100 \%$ \\
\hline 10 & Endoscopic characterisation with IEE avoids unnecessary biopsies for UGI superficial lesions & I & B & $97 \%$ \\
\hline
\end{tabular}


Table 4 Factors for risk stratification for esophageal and gastric cancer before and during endoscopy

\begin{tabular}{|c|c|c|}
\hline Diseases & $\begin{array}{l}\text { Before endoscopy } \\
\text { (clinical information) }\end{array}$ & $\begin{array}{l}\text { During endoscopy } \\
\text { (endoscopic finding) }\end{array}$ \\
\hline $\begin{array}{l}\text { Oesophageal } \\
\text { squamous cell } \\
\text { carcinoma (SCC) }\end{array}$ & $\begin{array}{l}\text { Male gender } \\
\text { Ethnic background } \\
\text { Alcohol drinking (especially with } \\
\text { face flushing) } \\
\text { Smoking } \\
\text { History and concomitant SCC }\end{array}$ & $\begin{array}{l}\text { Melanosis } \\
\text { Multiple Lugol voiding } \\
\text { lesions }\end{array}$ \\
\hline $\begin{array}{l}\text { Barrett's } \\
\text { adenocarcinoma }\end{array}$ & $\begin{array}{l}\text { Male gender } \\
\text { Caucasian ethnic background } \\
\text { Smoking }\end{array}$ & $\begin{array}{l}\text { Length of Barrett's } \\
\text { oesophagus } \\
\text { Lesions at the right } \\
\text { upper quadrant near the } \\
\text { oesophago-gastric junction } \\
\text { (OGJ) }\end{array}$ \\
\hline Gastric cancer & $\begin{array}{l}\text { Male gender } \\
\text { Family history } \\
\text { Ethnic background } \\
\text { History of oestrogen receptors } \\
\text { (ER) of gastric cancer } \\
\text { Helicobacter pylori infection } \\
\text { (especially with mucosal atrophy } \\
\text { and/or intestinal metaplasia) }\end{array}$ & $\begin{array}{l}\text { Endoscopic atrophy (Kimura- } \\
\text { Takemoto) } \\
\text { Endoscopic finding of } \\
\text { intestinal metaplasia (IM) }\end{array}$ \\
\hline
\end{tabular}

endoscopic resection (2 year cumulative incidence of $24.7 \%$; RR $7.4,95 \%$ CI 2.6 to 22$){ }^{2122}$

\section{Oesophageal adenocarcinoma}

A longer segment of columnar mucosa in Barrett's oesophagus is associated with a higher risk for high grade dysplasia (HGD) and adenocarcinoma. ${ }^{23-25}$ Some studies have reported that Barrett's neoplasia, especially in the short segment Barrett's oesophagus, developed more frequently in the area between 1 and 5 o'clock, which warrants careful endoscopic examination ${ }^{26-28}$ (figure 2C,D).

\section{Gastric adenocarcinoma}

Kimura and Takemoto characterised the endoscopic findings of atrophic mucosa in the corpus as areas with increased visibility of vessels, pale colour or low height ${ }^{29}$ (figure 3A,B). This characterisation marks an important distinction between atrophy and normal mucosa, where fundic glands are diminished or lost by chronic H. pylori infection, from non-atrophic fundic mucosa. ${ }^{30} 31$ The extent of endoscopic gastric mucosal atrophy correlates with the risk of gastric cancer. ${ }^{16}$ Gastric IM is a well-known precancerous condition (figure 4A,B). ${ }^{14} 32$ The extent of the IM is usually graded by systematic biopsies, ${ }^{33}$ but narrow band imaging (NBI), a recently-developed IEE technology, visualises gastric IM with high degrees of accuracy (sensitivity of $89 \%$ and specificity of $93 \%$ with the light blue crest sign, figure 4C,D). ${ }^{34}$ In contrast, endoscopic findings of regular arrangement of collecting venules (figure $3 \mathrm{C}, \mathrm{D})^{35}$ and fundic gland polyp ${ }^{36}$ are indicative of $H$. pylori naïve patients, suggesting a very low risk of gastric cancer. Endoscopic findings could be a good adjunct or even an alternative to the histological assessment of gastric cancer risk by multiple biopsies. ${ }^{37} 38$

\section{Statement 2: Presence or absence of premalignant mucosal changes during OGD should be documented \\ Level of evidence: III}

Level of recommendation: $\mathrm{C}$

Acceptance: $100 \%$

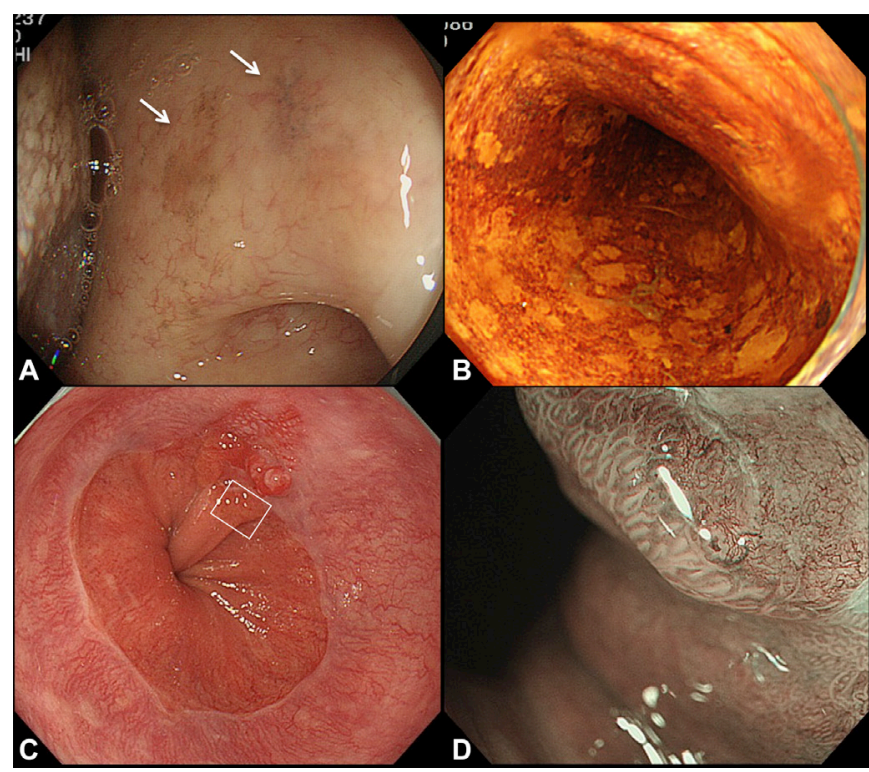

Figure 2 Melanosis is commonly seen in the soft oral palate ( $A$, white arrows) as well as in the oesophagus, indicating risk of presence of squamous cell carcinoma (SCC) in the oropharynx, larynx and oesophagus. (B) Multiple Lugol-voiding lesions in the background oesophageal mucosa predict subsequent development of metachronous oesophageal SCC after endoscopic resection of a primary lesion. (C) A case of intramucosal adenocarcinoma in the oesophago-gastric junction (OGJ). A reddish irregular mucosa presented at the 1 o'clock position of the OGJ. (D) Magnifying the narrow band image (NBI) (white box in C) identified an area with irregular microvessels and a demarcation line at the distal side of the lesion, suggesting the lesion was neoplastic.

As endoscopic diagnosis of premalignant conditions is associated with risks of upper GI neoplasia, the expert panel recommended documenting these findings. This information will assist clinicians managing their patients to recommend a surveillance programme for those at high risk. The ESGE guideline on the management of precancerous conditions and lesions in the stomach recommended surveillance endoscopy for patients with extensive atrophy and/orintestinal metaplasia at 3-year intervals. $^{3}$

\section{Statement 3.1: Use of sedation is recommended to enhance the detection rate of superficial neoplasm of the oesophagus and stomach}

Level of evidence: III

Level of recommendation: $\mathrm{C}$

Level of acceptance: $80 \%$

No studies have directly assessed the role of sedation on the endoscopic detection rate of superficial upper GI neoplasia. ${ }^{39} 40$ A systematic review has investigated the effect of sedation on the performance of endoscopy in 3918 patients from 16 studies. $^{41}$ One of the large placebo-controlled randomised controlled trials (RCTs) showed that midazolam and meperidine resulted in significantly better patient cooperation (79\% vs 19\%), satisfaction (79\% vs 47\%), and willingness to repeat the procedure $(81 \%$ vs $65 \%)$. A meta-analysis of two other RCTs confirmed that sedation resulted in significantly better patient satisfaction (RR 2.29, 95\% CI 1.16 to 4.53 ).

Although there was no direct evidence to support the use of sedation to enhance the detection of early upper GI neoplasm, the consensus panel recommended the use of sedation as it 


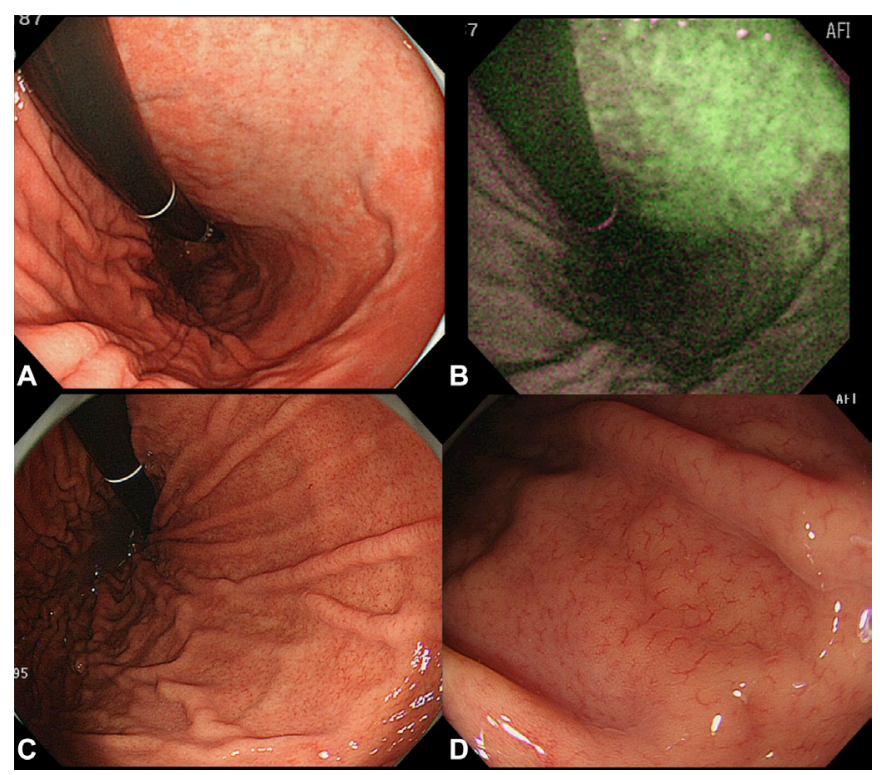

Figure 3 Patient with Helicobacter pylori-associated chronic atrophic gastritis. (A) In a white light image, atrophic mucosa with whitish colour and increased vessel visibility were seen in the lessor curvature of the corpus. (B) An auto-fluorescence image (AFI) showed the atrophic mucosa including the intestinal metaplasia as a greenish area. (C) Patient with neither $H$. pylori infection nor atrophic gastritis. The corpus mucosa looked homogeneously reddish and gastric folds were well preserved in whole circumference. (D) In the close view, regularly arranged collecting venules were seen.

improved patient acceptance and tolerance for surveillance OGD.

Statement 3.2: Use of an antispasmodic agent is recommended to enhance the detection rate of superficial neoplasm during OGD and IEE

Level of evidence: III

Level of recommendation: $\mathrm{C}$

Level of acceptance: $80 \%$

Two types of antispasmodic agents are commonly used for OGD: hyoscine/glucagoninjection, and topical spray of peppermint oil/L-menthol. No RCTs have been conducted on the use of hyoscine/glucagon for OGD. Intravenous hyoscine and glucagon is not widely used for diagnostic endoscopy because of its potential side effects and its cost. Topical peppermint oil was found to have an antispasmodic effect on the stomach comparable to that of hyoscine. ${ }^{42}{ }^{43}$ For L-menthol, the active extracts from peppermint oil, Hiki et al reported a dose-dependent effect in suppressing gastric peristalsis and a positive correlation with the endoscopist's ease of observation. ${ }^{44-46}$ None of the studies evaluated visual clarity, diagnostic yield or the detection rate of mucosal pathology.

Most experts commented that there was no evidence in the literature to support the use of antispasmodic agents in enhancing the detection of superficial upper GI neoplasia, but their use was recommended as there would be an indirect effect on the visual clarity of mucosal examination.

Statement 3.3: Use of mucolytic and/or defoaming agents is recommended for the improvement of visual clarity of OGD and IEE

Level of evidence: I

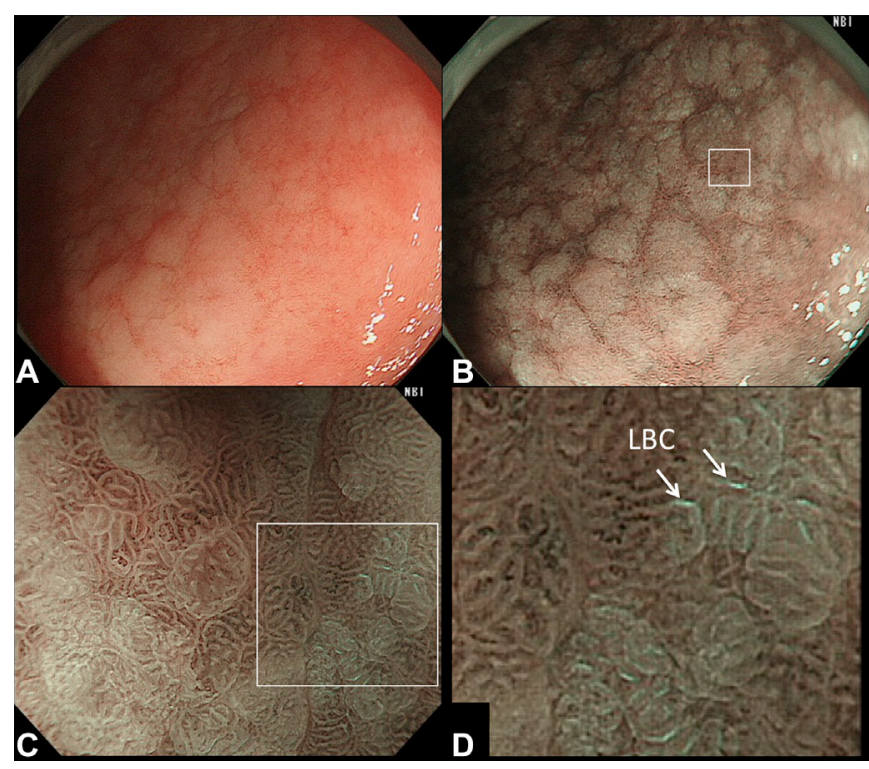

Figure 4 Patient with gastric intestinal metaplasia. (A) White light image showed slightly elevated whitish patches in the antrum. (B) A narrow band image (NBI) enhanced the presence of the whitish patches. ( $C$ and $D$ ) By magnifying the NBI image (white box in $B$ ), the light blue crest ( $L B C$ - which is defined as a fine blue-white line of light on the surface of the epithelium-is seen at the intestinal metaplasia.

Level of recommendation: A

Level of acceptance: $100 \%$

Three mucolytic/defoaming agents ( $\mathrm{N}$-acetylcysteine, pronase and simethicone) have been investigated in RCTs either as single or combination regimens. ${ }^{47-50}$ The use of simethicone (either alone or in combination) allows significantly better visual clarity under upper endoscopy. ${ }^{47-49}$ The addition of N-acetylcysteine did not increase mucosal visibility if simethicone was given beforehand. ${ }^{49} 51$ Two systematic reviews and meta-analyses yielded contradictory results regarding the addition of pronase to simethicone to improve mucosal clarity. ${ }^{5152}$ One recent RCT found that pronase significantly improved visibility in the proximal stomach and endoscopists' satisfaction compared with control $\left(\mathrm{P}=0.014\right.$ and $\mathrm{P}=0.034$, respectively). ${ }^{53}$ While the diagnostic performance of NBI endoscopy to detect IM did not differ in either group, the negative predictive value of NBI endoscopy showed a significant improvement over that of white light endoscopy (WLE) only in the pronase group $(\mathrm{P}=0.013)$. The consensus panel found that the current evidence supported the use of simethicone for improving visibility during OGD as one RCT had shown that pronase improved the negative prediction rate of IEE.

\section{Statement 4: Systematic endoscopic mapping of the entire oesophagus and stomach may improve the detection rate of UGI superficial neoplasm}

Level of evidence: III

Level of recommendation: $\mathrm{C}$

Level of acceptance: $100 \%$

The rate of missing an upper GI cancer during OGD was $2.3-13.9 \%$ in the West, and $>20 \%$ with regard to gastric cancer in Asia. ${ }^{55}$ A meta-analysis showed that $11.3 \%$ of upper GI cancers were missed during OGD performed up to 36 months before diagnosis. ${ }^{56}$ There are some locations of the upper GI tract where risks of missing cancer are high during OGD. ${ }^{262857}$ Endoscopic photo-mapping during OGD may decrease the possibility 
of missing lesions at these high-risk areas. Yao et al proposed a systematic screening protocol for the stomach (SSS). ${ }^{58}$ In this protocol, a total of 22 endoscopic photos from three to four quadrants at specific locations in the stomach would be taken either in a clockwise or counter-clockwise manner. A study from China reported that training in the diagnosis of EGC, which included a systematic inspection protocol that required at least 20 photographic images to be taken, improved the EGC detection rate from $0.2 \%$ to $2.3 \% .^{59}$

In summary, there was no well-designed study that directly evaluated the effect of systematic photo-mapping for OGD on improving the detection rate of superficial upper GI neoplasia. However, the panel agreed that systematic observation of the upper GI tract would improve the detection of superficial neoplasia by avoiding blind spots.

\section{Statement 5: Sufficient examination time is recommended to increase detection rate of upper GI superficial neoplasm}

Level of evidence: II

Level of recommendation: B

Level of acceptance: $89 \%$

Examination time remains one of the most subjective operator dependent aspects of diagnostic endoscopy. ${ }^{60}$ Ideally, the longer the examination time, the better the detection rate of significant pathologies during endoscopy. However, time is limited in clinical practice and lengthening procedures will likely result in a higher requirement for sedation and reduced patient tolerability. It will also have significant resource implications for endoscopy centres.

A multicentre prospective study revealed that lengthening $(>1 \mathrm{~min} / \mathrm{cm})$ the Barrett's inspection procedure resulted in a higher detection rate of HGD and adenocarcinoma $(\mathrm{P}=0.001) .{ }^{61}$ In a single-centre retrospective trial in Singapore, endoscopists who spent a mean OGD time of longer than 7 min were twice as likely to detect high-risk lesions (OR 2.50, 95\% CI 1.52 to 4.12 ) and three times as likely to detect neoplastic lesions (OR 3.42, $95 \%$ CI 1.25 to 10.38 ) than their counterparts who conducted shorter examinations. ${ }^{62}$ A similar Japanese study indicated that moderate $(5-7 \mathrm{~min})$ and slow $(>7 \mathrm{~min})$ endoscopists for OGD identified about twice as many neoplastic lesions (OR 1.90, $95 \%$ CI 1.06 to 3.40 , and 1.89 , 95\% CI 0.98 to 3.64 , respectively) than quicker ( $<5 \mathrm{~min})$ endoscopists. ${ }^{63}$ Park et al retrospectively analysed the data of 111962 patients who underwent OGD in a health-screening programme and found that slow endoscopists were more likely to detect gastric adenoma or carcinoma. $^{64}$

An adequate examination time plays an important role in enhancing the detection rate of early upper GI neoplasia. This will also serve as an important quality indicator for OGD among endoscopy centres. A systematic endoscopic observation of the upper GI tract, including the taking of a standard minimum number of photos, should take a procedural time of $8 \mathrm{~min}^{54}$

\section{Statement 6: Structured training improves the detection rate of upper GI superficial neoplasm \\ Level of evidence: II-3 \\ Level of recommendation: $\mathrm{C}$ \\ Level of acceptance: $97 \%$}

The diagnosis of early GI neoplasia is a two-step process which requires endoscopists to identify the suspicious lesion and differentiate its pathology. Training in endoscopic diagnosis should not merely seek to improve technical skills, but should also include a cognitive- and knowledge-based protocol.
A prospective RCT showed in-classroom teaching on NBI diagnosis for Barrett's neoplasm yielded a higher percentage of high-confidence answers to diagnosis than self-directed web learning, but there was no difference in overall accuracy between the two learning groups. The authors concluded that self-directed web learning may be adequate because it can be accessed and repeated at any time. ${ }^{65} \mathrm{~A}$ multicentre prospective study showed that a web-based video learning programme for NBI diagnosis of precancerous gastric lesions produced an improvement in global accuracy, specificity for gastric IM and sensitivity for dysplasia. ${ }^{66}$ Mabe et al demonstrated a significant improvement in test scores for magnifying NBI diagnosis of EGC after an educational lecture on vessel plus surface (VS) classification. ${ }^{67}$ Yao et al developed an e-learning programme on the detection of EGC in WLE ${ }^{68}$ and investigated its usefulness in an RCT that enrolled 332 endoscopists from 35 countries around the world. ${ }^{69}$ The improvement of test scores in the e-learning group was significantly higher than in the non-e-learning group. Although most studies indicated an improvement in test results for e-learning, one observational study suggested the effectiveness of a voluntary training programme in increasing the detection rate of EGC in a 'real-world' clinical setting. ${ }^{70}$

Structured training improves the knowledge and recognition skills of endoscopists in the diagnosis of early upper GI cancers. This in turn should improve the effectiveness of endoscopic detection and characterisation of the disease in clinical practice.

\section{Statement 7.1: IEE in addition to WLI improves the detection rate for oesophageal superficial neoplasm}

Level of evidence: I

Level of recommendation: A

Level of acceptance: $100 \%$

There are two main types of IEE: dye-based IEE (chromoendoscopy) and equipment-based IEE, which includes techniques such as NBI, flexible spectral imaging colour enhancement (FICE), blue laser/light imaging (BLI), i-SCAN and optical enhancement i-SCAN. ${ }^{71}$ Iodine chromoendoscopy enhances the detection of superficial oesophageal SCC as an iodine-unstained area, especially when it cannot be observed in WLE. ${ }^{72}$ Iodine chromoendoscopy increases sensitivity for dysplastic/cancerous lesions to $96 \%$ compared with only $62 \%$ with WLE. A multicentre prospective RCT demonstrated that NBI detected superficial oesophageal SCC more frequently than WLI (97\% v 55\%, $\mathrm{P}<0.001$ ) (figure 6). ${ }^{73}$ In a multicentre RCT comparing high definition WLE with NBI for the detection of Barrett's neoplasm, NBI detected more dysplastic areas (30\% vs $21 \%, \mathrm{P}=0.01)$ than WLE. ${ }^{74}$ A meta-analysis concluded that IEE increased the diagnostic yield for detection of dysplasia or cancer by 34\% (95\% CI $20 \%$ to $56 \% ; \mathrm{P}<0.0001) .^{75}$ IEE improves the detection rate of both superficial oesophageal SCC and Barrett's oesophagus associated dysplasia.

Statement 7.2: IEE in addition to WLI improves the detection rate of gastric premalignant mucosal changes such as gastric intestinal metaplasia and atrophy

Level of evidence: I

Level of recommendation: A

Level of acceptance: $93 \%$

A multicentre RCT reported that detection of gastric IM was significantly higher using NBI compared with WLE $(17.7 \%$ vs $7.7 \%, \mathrm{P}<0.001$, figure 5). ${ }^{76}$ Another single centre RCT showed that NBI significantly increased the detection of IM and gastric atrophy. ${ }^{77}$ Endoscopic trimodal imaging using auto-fluorescence 


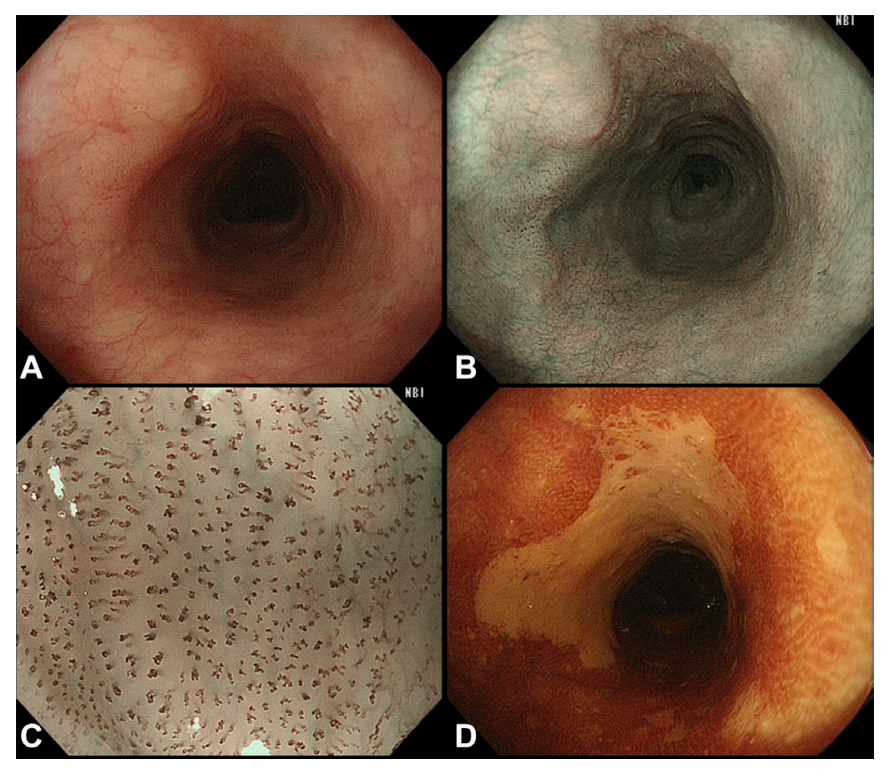

Figure 5 Patient with superficial oesophageal squamous cell carcinoma. (A) White light image did not show obvious mucosal changes. (B) In a narrow band image, slightly brownish areas were seen from 9 to 12 o'clock site. (C) Magnifying observation in the brownish area revealed irregular microvessels. The irregular microvessels maintained a loop structure and they were observed as 'brownish dots'. (D) lodine chromoendoscopy clearly visualised the lesion as a nonstaining area.

imaging (AFI) followed by NBI also increased the detection rate of IM (figure $3 \mathrm{~B}$ ). ${ }^{78}$ These RCTs supported the initial results from a number of prospective non-randomised tandem studies. ${ }^{79} 80$ In the case of gastric neoplasm, two non-randomised prospective crossover studies suggested that trimodal imaging can increase the detection rate of gastric neoplasm over WLE alone. ${ }^{81} 82 \mathrm{~A}$ retrospective study reported that trimodal imaging significantly reduced the frequency of missed synchronous gastric lesions when compared with WLI $(2.3 \%$ vs $9.3 \%, \mathrm{P}<0.01) .^{83}$ Accordingly, there is robust evidence that IEE increased the detection rate of premalignant gastric pathologies.

\section{Statement 8: IEE in addition to WLI is useful for the delineation of UGI superficial neoplasia \\ Level of evidence: II-2 \\ Level of recommendation: B \\ Level of acceptance: 97\%}

Dye-based IEE without magnification in addition to WLI for the characterisation of superficial oesophageal neoplasm

Oesophageal HGD and carcinoma appear as non-stained areas with a pinkish colour with iodine-based chromoendoscopy. ${ }^{84}$ One observational study indicated that iodine chromoendoscopy improved lesion delineation in $88 \%$ of cases involving oesophageal HGD or SCC. ${ }^{85}$ Expert endoscopists proposed that iodine chromoendoscopy is indispensable for the accurate delineation of oesophageal SCCs, enabling the borders of the lesion to be accurately established before endoscopic treatment. ${ }^{86} 87$ Recent ESGE guidelines also supported the use of iodine chromoendoscopy especially during performance of endoscopic submucosal dissection (ESD) to delineate tumour margins. ${ }^{88}$
Dye-based IEE without magnification in addition to WLI may be useful for the characterisation of early gastric neoplasm

Chromoendoscopy with indigo carmine contrasts the surface topography of the gastric mucosa, provides better recognition of morphological characteristics and improves lesion characterisation and delineation. Accurate morphological characterisation may facilitate targeted biopsy as well as margin delineation for endoscopic resection.

Indigo carmine can be used separately or in combination with acetic acid. ${ }^{89-92}$ A meta-analysis showed that any chromoendoscopy including indigo carmine was superior to WLE for diagnosis of EGC in terms of sensitivity and specificity, and that the addition of acetic acid further improved diagnostic accuracy. ${ }^{93}$ Several observational studies have indicated the usefulness of combining indigo carmine with acetic acid for delineation of EGC. A recent multicentre RCT showed that the diagnostic performance of indigo carmine chromoendoscopy was similar to that of magnifying NBI for delineating EGC. ${ }^{94}$

The performance of chromoendoscopy requires the preparation of dye, but it does not require the use of specialised and expensive equipment. Moreover, the preparatory time for chromoendoscopy should be reasonable. Hence the consensus panel recommended the use of chromoendoscopy for characterisation and delineation of EGC.

Equipment-based IEE without magnification for the characterisation of superficial oesophageal neoplasm

When non-magnifying NBI was compared with iodine chromoendoscopy for the detection of oesophageal SCC, NBI demonstrated higher accuracy $(77 \%$ vs $68 \%, \mathrm{P}=0.03)$ and specificity (75.2\% vs $64 \%, \mathrm{P}=0.01) .{ }^{95}$ In the opinion of the expert panel, IEE can achieve better delineation of the tumour extent for superficial oesophageal neoplasia. However, further well-designed studies will be needed to quantify its efficacy.

Equipment-based IEE without magnification for the characterisation of early gastric neoplasm

New-generation IEEs (second-generation NBI and BLI) provide brighter endoscopic images that enable an overview to be gained of the entire gastric mucosa. Pimentel-Nunes et al proposed diagnostic criteria to characterise gastric premalignant lesions including chronic gastritis, IM and carcinoma using non-magnifying NBI, ${ }^{96}$ and these criteria were validated in a multicentre prospective cohort study. ${ }^{37}$ One observational study indicated that diagnostic accuracy for differentiating adenocarcinoma from benign gastric lesions was significantly higher in non-magnification NBI than in WLE (92.3\% vs 61.5\%). ${ }^{97}$ At present, the consensus panel recommended the use of equipment-based IEE without magnification for characterisation and delineation of EGC as evidenced by the accuracy of IEE without magnification demonstrated in prospective cohort studies. ${ }^{9697}$

\section{Statement 9: Magnifying endoscopy with NBI is recommended for better characterisation of upper GI superficial neoplasm}

Level of evidence: I

Level of recommendation: A

Level of acceptance: $100 \%$

\section{Oesophageal SCC}

A multicentre RCT showed the superiority of magnifying NBI for the diagnosis of superficial oesophageal SCC compared with 


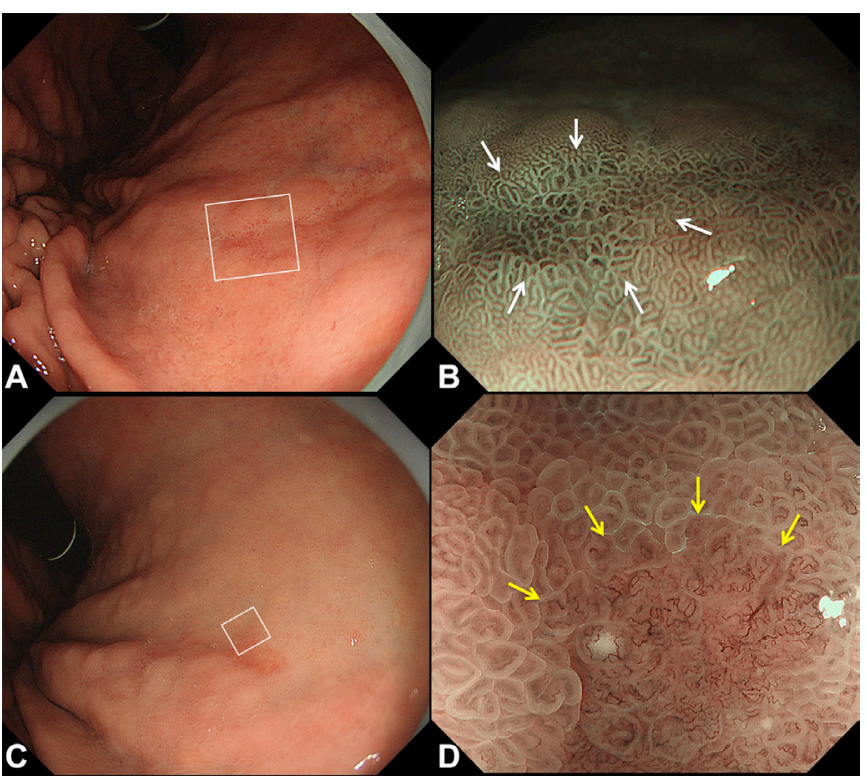

Figure 6 A case of Helicobacter pylori associated chronic atrophic gastritis. (A) A small depressed lesion was found in the gastric corpus. (B) In a magnifying narrow band image (NBI) (white box in A), the lesion was demarcated but there were regular microsurface and regular microvessels within the demarcation line (white arrows). (C) A case of small early gastric cancer. A small reddish area was seen in the gastric corpus. (D) In a magnifying NBI image (white box in C), the lesion was demarcated (yellow arrows) and there were irregular microvessels within the demarcation line.

conventional WLE with accuracy similar to histological diagnosis on biopsy (figure $5 \mathrm{c}$ ). ${ }^{7398}$

\section{Oesophageal adenocarcinoma}

Two systematic reviews indicated that magnifying NBI had high diagnostic precision for HGD in Barrett's oesophagus, based on an irregular microsurface and/or an irregular microvascular pattern. ${ }^{99} 100$

\section{Gastric adenocarcinoma}

A multicentre RCT demonstrated that a combination of WLE and magnifying NBI for small depressed type EGC achieved sensitivity of $95.0 \%$, specificity of $96.8 \%$ and accuracy of $96.6 \%$. These results were significantly better than those achieved with WLE or magnifying NBI alone (figure 6). ${ }^{101} 102$ A multicentre prospective cohort study using VS classification confirmed the excellent diagnostic performance of magnifying NBI for the diagnosis of EGC, with accuracy, sensitivity and specificity of $98.1 \%, 85.7 \%$ and $99.4 \%$, respectively. ${ }^{103}$ In VS classification, the presence and absence of (1) a demarcation line and (2) an irregular microvessel pattern and/or irregular surface pattern were evaluated. Three meta-analyses support the efficacy of magnifying endoscopy for diagnosis of EGC. ${ }^{104-106}$ Based on these results, experts recommended the algorithm 'magnifying endoscopy simple diagnostic algorithm for early gastric cancer (MESDA-G)' to enhance the detection and characterisation of early gastric cancers (figure 7$).{ }^{107}$

\section{Statement 10: Endoscopic characterisation with IEE avoids unnecessary biopsies for upper GI superficial lesions \\ Level of evidence: I}

Level of recommendation: B

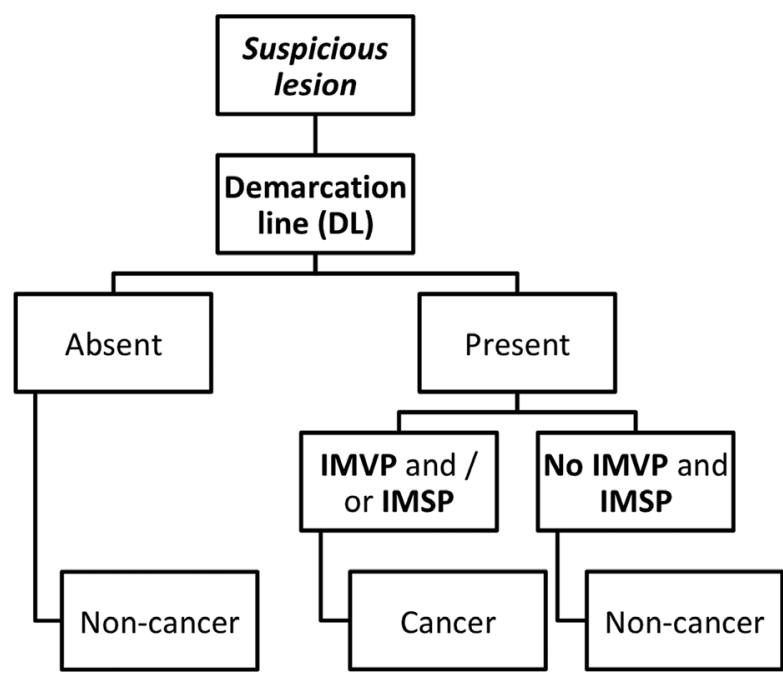

Figure 7 Magnifying endoscopy simple diagnostic algorithm for early gastric cancer (MESDA-G). A suspicious lesion is assessed for the presence or absence of a demarcation line and/or irregular colour or surface in white light endoscopy. First, the lesion is evaluated for a demarcation line. If it is not present we can confidently make a diagnosis of 'non-cancer'. When the lesion has a demarcation line, the presence (or absence) of an irregular microstructure and/or microvessel patterns are essential to make a diagnosis of cancer (or non-cancer). IMSP; irregular microsurface pattern; IMVP, irregular microvessel pattern.

\section{Level of acceptance: $97 \%$}

Biopsy from a suspicious lesion is necessary to prove it is a neoplasm that requires treatment. However, it is possible to avoid biopsy if endoscopic diagnosis provides a high rate of accuracy for benign lesion diagnosis as well as a high rate of negative predictive value of malignant change.

\section{Oesophageal SCC}

A prospective cohort study revealed that NBI and probe-based confocal laser endomicroscopy (pCLE) both provided excellent diagnostic accuracy and reduced the number of biopsies needed to be taken for diagnosis in iodine non-stained areas representing the presence of early oesophageal SCC. ${ }^{108}$

\section{Oesophageal adenocarcinoma}

Sharma et al conducted a multicentre RCT that compared high definition WLE using four quadrant biopsies every $2 \mathrm{~cm}$, together with targeted biopsies from visible lesions (Seattle protocol) with NBI for detection of IM and Barrett's neoplasia. ${ }^{74}$ The study showed that both WLI and NBI detected 104/113 (92\%) patients with IM, but NBI required fewer biopsies per patient (3.6 vs 7.6, $\mathrm{P}<0.0001) .^{74}$ The recent meta-analysis concluded that NBI was useful for the diagnosis of dysplasia in Barrett's oesophagus, with sensitivity at $91 \%$ and specificity at $95 \% .{ }^{109}$ This fulfils the Preservation and Incorporation of Valuable Endoscopic Innovations (PIVI) criteria. ${ }^{110}$ However, it should be noted that the latest guideline in 2016 by the American College of Gastroenterology recommended that at least eight biopsies should be taken in patients with Barrett's oesophagus. ${ }^{111}$

\section{Gastric adenocarcinoma}

A prospective cohort study showed that the use of magnifying NBI could reduce the number of biopsies required for the detection of $\mathrm{EGC}^{103}$ (figure 8). 


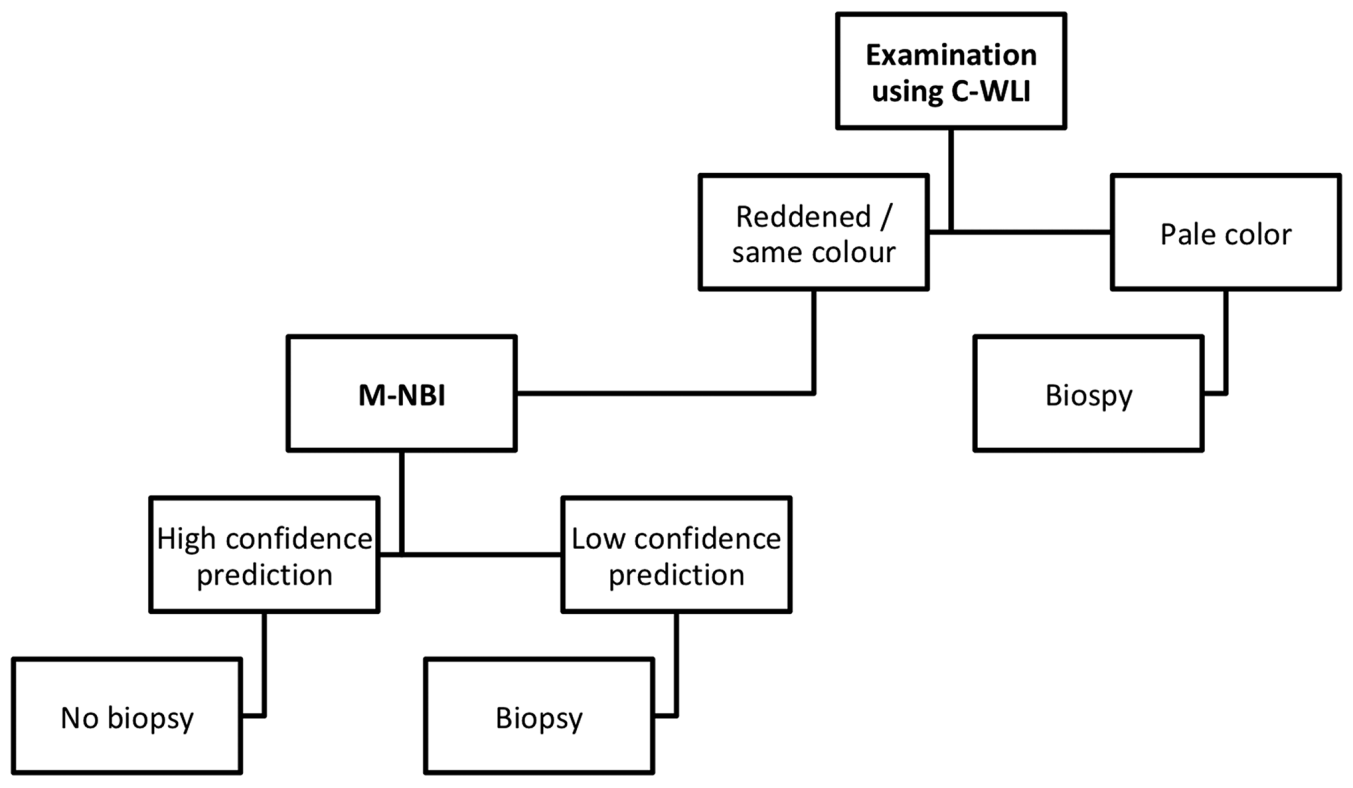

Figure 8 Strategy of biopsy for screening gastroscopy with magnifying narrow band imaging (NBI). The entire gastric mucosa is screened with white light endoscopy for a suspicious lesion. When the lesion is a pale colour, a biopsy is performed from the lesion. When the lesion looks reddish, it is evaluated with magnifying NBI for the presence and absence of a demarcation line and/or an irregular microsurface/microvessel pattern. If the diagnosis cannot be made with high confidence, the biopsy is recommended. If the diagnosis is made with high confidence, especially if it is benign, a biopsy could be avoided. C-WLI, conventional white light endoscopy; M-NBI, magnifying narrow band imaging.

\section{DISCUSSION}

Upper GI cancers are difficult to recognise at the early stage. Chadwick et al studied a cohort of 2727 patients who had gastric cancer and reported that $8.3 \%$ had received an upper endoscopy 3 to 36 months before diagnosis. ${ }^{112}$ There are multiple reasons for missing early upper GI cancers during endoscopy. Most of these early cancers are only represented by subtle changes in microstructural and microvascular patterns, and the inability to recognise these changes during endoscopy could be related to inadequate training, limited use of IEE, and an insufficiently systematic approach involving incomplete examination and inadequate preparation of the mucosa to enhance recognition. The current consensus on diagnostic upper GI endoscopy aims to unify clinical practice, as well as improve the quality and standards in diagnostic endoscopy.

Recently, the British Society of Gastroenterology (BSG) and the Association of Upper Gastrointestinal Surgeons of Great Britain and Ireland (AUGIS) published a position statement on quality standards in upper GI endoscopy. ${ }^{113}$ These statements were developed according to the patient management pathway, including pre-procedure, procedure, disease specific and post-procedure management issues. This quality standards position statement differs from our current Asian consensus, in that the Asian consensus focused on endoscopic diagnosis of early GI neoplasia while the quality standards position statement was established from a general approach to the performance of diagnostic endoscopy. As far as improvements in diagnostic endoscopy are concerned, the two statements are complementary. The BSG statement is aimed at ensuring a systematic approach to diagnosis and requires photographic documentation at relevant anatomical landmarks and recognised lesions, adequate mucosal visualisation, and inspection time during a diagnostic OGD to be recorded for surveillance procedures. This Asian consensus will standardise the procedure and approach to the recognition and characterisation of early upper GI neoplasia.
The Western endoscopy societies have issued practice guidelines for endoscopic management of premalignant and malignant condition/lesions in the oesophagus ${ }^{114} 115$ and the stomach. ${ }^{116}$ Most guidelines recommend use of WLE and/or random biopsies to make a diagnosis of those premalignant lesions, but they do not include endoscopic practice for detection and characterisation of early upper GI cancers using IEE. The management of precancerous conditions and lesions in the stomach (MAPS) guideline ${ }^{3}$ suggested use of NBI with/without magnifying endoscopy, but it was not strongly endorsed because of limited evidence at that time. Accumulated recent evidence on IEE was reflected in this consensus. Because this consensus was drafted from Asian experts, the consensus may be more applicable among Asian countries, especially where the incidence of gastric cancer and squamous oesophageal cancer is moderate to high. However, when the expert panel developed the consensus, differences among Asian countries or between East and West were not considered. We believe that this consensus will lead to an improvement in diagnostic endoscopy by standardising the procedures, preparation and training around the world.

\footnotetext{
Author affiliations

'Department of Surgery, The Chinese University of Hong Kong, Hong Kong ${ }^{2}$ Department of Gastrointestinal Oncology, Osaka International Cancer Institute, Osaka, Japan

${ }^{3}$ Department of Gastroenterology, Lyell McEwin and Modbury Hospital, University of Adelaide, Adelaide, South Australia, Australia

${ }^{4}$ Department of Gastroenterology and Hepatology, Nihon University School of Medicine, Tokyo, Japan

${ }^{5}$ Department of Endoscopy, University Chikushi Hospital, Fukuoka, Japan

${ }^{6}$ Department of Gastroenterology and Hepatology, Changi General Hospital, Singapore

${ }^{7}$ Department of Medicine, University of Malaya, Kuala Lumpur, Malaysia

${ }^{8}$ Department of Gastroenterology, Toranomon Hospital, Tokyo, Japan

${ }^{9}$ Institute and Hospital, Chinese Academy of Medical Sciences, Beijing, China

${ }^{10}$ Division of Gastroenterology, Department of Medicine, Faculty of Medicine,

Chulalongkorn University and King Chulalongkorn Memorial Hospital The Thai Red

Cross, Bangkok, Thailand

${ }^{11}$ Department of Gastroenterology, Dokkyo Medical University, Tochigi, Japan
} 
${ }^{12}$ Department of Innovative Interventional Endoscopy Research, Jikei University School of Medicine, Tokyo, Japan

${ }^{13}$ Digestive Diseases Center, Showa University Koto-Toyosu Hospital, Tokyo, Japan

Contributors PWYC is responsible for overall coordination and planning of the consensus meetings, drafting and critical appraisal of statement 6 , writing and editing of the manuscript. NU is responsible for drafting and critical appraisal of statement 1 as well as writing and editing of the manuscript. RS is responsible for drafting and critical appraisal of statement 1 and the manuscript, as well as participation as an expert in the consensus meeting. TG is responsible for drafting and critical appraisal of statement 2 and the manuscript, as well as participation as an expert in the consensus meeting. EKWN is responsible for drafting and critical appraisal of statement 3 and the manuscript, as well as participation as an expert in the consensus meeting. $\mathrm{KY}$ is responsible for drafting and critical appraisal of statement 9 and the manuscript, as well as participation as an expert in the consensus meeting. TLA is responsible for drafting and critical appraisal of statement 7 and the manuscript, as well as participation as an expert in the consensus meeting. SHH is responsible for drafting and critical appraisal of statement 5 and the manuscript, as well as participation as an expert in the consensus meeting. DK is responsible for drafting and critical appraisal of statement 8 and the manuscript as well as participation as an expert in the consensus meeting. FY is responsible for drafting and critical appraisal of statement 4 and the manuscript, as well as participation as an expert in the consensus meeting. RP is responsible for drafting and critical appraisal of statement 10 and the manuscript, as well as participation as an expert in the consensus meeting. KG is responsible for drafting and critical appraisal of statement 8 and the manuscript, as well as participation as an expert in the consensus meeting. JYWL, HT, HI is responsible for drafting and critical appraisal of the manuscript, as well as participation as an expert in the consensus meeting.

Funding The authors have not declared a specific grant for this research from any funding agency in the public, commercial or not-for-profit sectors.

Competing interests The consensus meeting is supported by a non-government organisation named Asian Novel Bio-Imaging and Intervention Group (ANBIG) which focused on training and education of endoscopic diagnosis and management of early gastrointestinal cancers in Asia. All the authors are members of ANBIG. The manuscript underwent editorial review by a professional academic English editor.

Patient consent Not required.

Provenance and peer review Not commissioned; externally peer reviewed.

Open access This is an open access article distributed in accordance with the Creative Commons Attribution Non Commercial (CC BY-NC 4.0) license, which permits others to distribute, remix, adapt, build upon this work non-commercially, and license their derivative works on different terms, provided the original work is properly cited, appropriate credit is given, any changes made indicated, and the use is non-commercial. See: http://creativecommons.org/licenses/by-nc/4.0/.

\section{REFERENCES}

1 The International Agency for Research on Cancer. Cancer today, GLOBOCAN2018. 2018. http://gco.iarc.fr/today/home

2 Lam-Himlin D. Management of precancerous conditions and lesions in the stomach (MAPS): guideline from the European Society of Gastrointestinal Endoscopy (ESGE), European Helicobacter Study Group (EHSG), European Society of Pathology (ESP), and the Sociedade Portuguesa de Endoscopia Digestiva (SPED). Yearbook of Pathology and Laboratory Medicine 2013;2013:44.

3 Lee CH, Lee JM, Wu DC, et al. Independent and combined effects of alcohol intake, tobacco smoking and betel quid chewing on the risk of esophageal cancer in Taiwan. Int J Cancer 2005;113:475-82.

4 Eng MY, Luczak SE, Wall TL. ALDH2, ADH1B, and ADH1C genotypes in Asians: a literature review. Alcohol Res Health 2007;30:22-7.

5 Harada S, Agarwal DP, Goedde HW. Aldehyde dehydrogenase deficiency as cause of facial flushing reaction to alcohol in Japanese. Lancet 1981;2:982.

6 Yokoyama A, Kato H, Yokoyama T, et al. Genetic polymorphisms of alcohol and aldehyde dehydrogenases and glutathione S-transferase M1 and drinking, smoking, and diet in Japanese men with esophageal squamous cell carcinoma. Carcinogenesis 2002:23:1851-9.

7 Shiozaki H, Tahara H, Kobayashi K, et al. Endoscopic screening of early esophageal cancer with the Lugol dye method in patients with head and neck cancers. Cancer 1990;66:2068-71.

8 Takenaka R, Kawahara Y, Okada H, et al. Narrow-band imaging provides reliable screening for esophageal malignancy in patients with head and neck cancers. Am J Gastroenterol 2009;104:2942-8.

9 El-Serag HB, Mason AC, Petersen N, et al. Epidemiological differences between adenocarcinoma of the oesophagus and adenocarcinoma of the gastric cardia in the USA. Gut 2002:50:368-72.

10 Hardikar S, Onstad L, Blount PL, et al. The role of tobacco, alcohol, and obesity in neoplastic progression to esophageal adenocarcinoma: a prospective study of Barrett's esophagus. PLoS One 2013;8:e52192.
11 Coleman HG, Bhat S, Johnston BT, et al. Tobacco smoking increases the risk of high-grade dysplasia and cancer among patients with Barrett's esophagus. Gastroenterology 2012;142:233-40.

12 International Agency for Research on Cancer. GLOBOCAN 2012: Estimated Cancer Incidence, Mortality and Prevalence Worldwide in 2012. 2017. http://globocan.iarc fr/Pages/fact sheets cancer.aspx

13 Yaghoobi M, Bijarchi R, Narod SA. Family history and the risk of gastric cancer. Br J Cancer 2010;102:237-42.

14 Correa P. Human gastric carcinogenesis: a multistep and multifactorial process-First American Cancer Society Award Lecture on Cancer Epidemiology and Prevention. Cancer Res 1992:52:6735-40.

15 Kato S, Matsukura N, Tsukada K, et al. Helicobacter pylori infection-negative gastric cancer in Japanese hospital patients: incidence and pathological characteristics. Cancer Sci 2007:98:790-4.

16 Uemura N, Okamoto S, Yamamoto S, et al. Helicobacter pylori infection and the development of gastric cancer. N Eng/ J Med Overseas Ed 2001;345:784-9.

17 Fukase K, Kato M, Kikuchi S, et al. Effect of eradication of Helicobacter pylori on incidence of metachronous gastric carcinoma after endoscopic resection of early gastric cancer: an open-label, randomised controlled trial. Lancet 2008;372:392-7

18 Yoon SB, Park JM, Lim CH, et al. Effect of Helicobacter pylori eradication on metachronous gastric cancer after endoscopic resection of gastric tumors: a metaanalysis. Helicobacter 2014;19:243-8.

19 Yokoyama A, Omori T, Yokoyama T, et al. Esophageal melanosis, an endoscopic finding associated with squamous cell neoplasms of the upper aerodigestive tract, and inactive aldehyde dehydrogenase-2 in alcoholic Japanese men. J Gastroenterol 2005;40:676-84

20 Muto M, Hironaka S, Nakane M, et al. Association of multiple Lugol-voiding lesions with synchronous and metachronous esophageal squamous cell carcinoma in patients with head and neck cancer. Gastrointest Endosc 2002;56:517-21.

21 Hori K, Okada H, Kawahara Y, et al. Lugol-voiding lesions are an important risk factor for a second primary squamous cell carcinoma in patients with esosphageal cancer or head and neck cancer. Am J Gastroenterol 2011;106:858-66.

22 Katada C, Yokoyama T, Yano T, et al. Alcohol consumption and multiple dysplastic lesions increase risk of squamous cell carcinoma in the esophagus, head, and neck. Gastroenterology 2016;151:860-9.

23 Bhat S, Coleman HG, Yousef F, et al. Risk of malignant progression in Barrett's esophagus patients: results from a large population-based study. J Nat/ Cancer Inst 2011:103:1049-57.

24 Sikkema M, de Jonge PJ, Steyerberg EW, et al. Risk of esophageal adenocarcinoma and mortality in patients with Barrett's esophagus: a systematic review and metaanalysis. Clin Gastroenterol Hepatol 2010;8:235-44.

25 Thomas T, Abrams KR, De Caestecker JS, et al. Meta analysis: cancer risk in Barrett's oesophagus. Aliment Pharmacol Ther 2007;26:1465-77.

26 Kariyawasam VC, Bourke MJ, Hourigan LF, et al. Circumferential location predicts the risk of high-grade dysplasia and early adenocarcinoma in short-segment Barrett's esophagus. Gastrointest Endosc 2012;75:938-44.

27 Cassani L, Sumner E, Slaughter JC, et al. Directional distribution of neoplasia in Barrett's esophagus is not influenced by distance from the gastroesophageal junction. Gastrointest Endosc 2013:77:877-82.

28 Enestvedt BK, Lugo R, Guarner-Argente C, et al. Location, location, location: does early cancer in Barrett's esophagus have a preference? Gastrointest Endosc 2013:78:462-7.

29 Kimura K, Takemoto T. An endoscopic recognition of the atrophic border and its significance in chronic gastritis. Endoscopy 1969;1:87-97.

30 Kimura K. Chronological transition of the fundic-pyloric border determined by stepwise biopsy of the lesser and greater curvatures of the stomach. Gastroenterology 1972;63:584-92.

31 Dixon MF, Genta RM, Yardley JH, et al. Classification and grading of gastritis. The updated Sydney System. International Workshop on the Histopathology of Gastritis, Houston 1994. Am J Surg Pathol 1996;20:1161-81.

32 Correa P, Piazuelo MB, Wilson KT. Pathology of gastric intestinal metaplasia: clinical implications. Am J Gastroenterol 2010;105:493-8.

33 Capelle LG, de Vries AC, Haringsma J, et al. The staging of gastritis with the OLGA system by using intestinal metaplasia as an accurate alternative for atrophic gastritis. Gastrointest Endosc 2010;71:1150-8.

34 Uedo $\mathrm{N}$, Ishihara $\mathrm{R}$, lishi $\mathrm{H}$, et al. A new method of diagnosing gastric intestinal metaplasia: narrow-band imaging with magnifying endoscopy. Endoscopy 2006;38:819-24

35 Yagi K, Nakamura A, Sekine A. Characteristic endoscopic and magnified endoscopic findings in the normal stomach without Helicobacter pylori infection. J Gastroenterol Hepatol 2002;17:39-45.

36 Kato T, Yagi N, Kamada T, et al. Diagnosis of Helicobacter pylori infection in gastric mucosa by endoscopic features: a multicenter prospective study. Dig Endosc 2013:25:508-18

37 Pimentel-Nunes $P$, Libânio $D$, Lage J, et al. A multicenter prospective study of the real-time use of narrow-band imaging in the diagnosis of premalignant gastric conditions and lesions. Endoscopy 2016;48:723-30. 
38 Buxbaum JL, Hormozdi D, Dinis-Ribeiro M, et al. Narrow-band imaging versus white light versus mapping biopsy for gastric intestinal metaplasia: a prospective blinded trial. Gastrointest Endosc 2017;86:857-65.

39 Abraham NS, Fallone CA, Mayrand S, et al. Sedation versus no sedation in the performance of diagnostic upper gastrointestinal endoscopy: a Canadian randomized controlled cost-outcome study. Am J Gastroentero/ 2004;99:1692-9.

40 Lee MG, Hanna W, Harding H. Sedation for upper gastrointestinal endoscopy: a comparative study of midazolam and diazepam. Gastrointest Endosc 1989;35:82-4.

41 McQuaid KR, Laine L. A systematic review and meta-analysis of randomized, controlled trials of moderate sedation for routine endoscopic procedures. Gastrointest Endosc 2008;67:910-23.

42 Hikichi T, Irisawa A, Sato M, et al. Utility of peppermint oil for endoscopic diagnosis of gastric tumors. Fukushima J Med Sci 2011;57:60-5.

43 Hiki N, Kurosaka $\mathrm{H}$, Tatsutomi Y, et al. Peppermint oil reduces gastric spasm during upper endoscopy: a randomized, double-blind, double-dummy controlled trial. Gastrointest Endosc 2003;57:475-82

44 Hiki N, Kaminishi M, Yasuda K, et al. Multicenter phase II randomized study evaluating dose-response of antiperistaltic effect of L-menthol sprayed onto the gastric mucosa for upper gastrointestinal endoscopy. Dig Endosc 2012;24:79-86.

45 Hiki N, Kaminishi M, Yasuda K, et al. Antiperistaltic effect and safety of L-menthol sprayed on the gastric mucosa for upper GI endoscopy: a phase III, multicenter, randomized, double-blind, placebo-controlled study. Gastrointest Endosc 2011;73:932-41.

46 Fujishiro M, Kaminishi M, Hiki N, et al. Efficacy of spraying I-menthol solution during endoscopic treatment of early gastric cancer: a phase III, multicenter, randomized, double-blind, placebo-controlled study. J Gastroenterol 2014;49:446-54.

47 Neale JR, James S, Callaghan J, et al. Premedication with N-acetylcysteine and simethicone improves mucosal visualization during gastroscopy: a randomized, controlled, endoscopist-blinded study. Eur J Gastroenterol Hepatol 2013;25:778-83

48 Chang WK, Yeh MK, Hsu HC, et al. Efficacy of simethicone and N-acetylcysteine as premedication in improving visibility during upper endoscopy. J Gastroenterol Hepatol 2014;29:769-74.

49 Song M, Kwek AB, Law NM, et al. Efficacy of small-volume simethicone given at least 30 min before gastroscopy. World J Gastrointest Pharmacol Ther 2016;7:572-8

50 Lee GJ, Park SJ, Kim SJ, et al. Effectiveness of premedication with pronase for visualization of the mucosa during endoscopy: a randomized, controlled trial. Clin Endosc 2012;45:161-4.

51 Chen HW, Hsu HC, Hsieh TY, et al. Pre-medication to improve esophagogastroduodenoscopic visibility: a meta-analysis and systemic review. Hepatogastroenterology 2014;61:1642-8.

$52 \mathrm{Kim}$ GH, Cho YK, Cha JM, et al. Efforts to increase image quality during endoscopy: the role of pronase. World J Gastrointest Endosc 2016;8:267-72.

53 Cha JM, Won KY, Chung IK, et al. Effect of pronase premedication on narrow-band imaging endoscopy in patients with precancerous conditions of stomach. Dig Dis SC 2014;59:2735-41.

54 Veitch AM, Uedo N, Yao K, et al. Optimizing early upper gastrointestinal cancer detection at endoscopy. Nat Rev Gastroenterol Hepatol 2015;12:660-7.

55 Ren W, Yu J, Zhang ZM, et al. Missed diagnosis of early gastric cancer or high-grade intraepithelial neoplasia. World J Gastroenterol 2013;19:2092-6.

56 Menon S, Trudgill N. How commonly is upper gastrointestinal cancer missed at endoscopy? A meta-analysis. Endosc Int Open 2014;2:E46-E50.

57 Pech O, Gossner L, Manner H, et al. Prospective evaluation of the macroscopic types and location of early Barrett's neoplasia in 380 lesions. Endoscopy 2007:39:588-93.

58 Yao K. The endoscopic diagnosis of early gastric cancer. Ann Gastroenterol 2013:26:11-22.

59 Zhang Q, Chen Z-yu, Chen C-di, et al. Training in early gastric cancer diagnosis improves the detection rate of early gastric cancer. Medicine 2015;94:e384.

60 Uedo N, Gotoda T, Yoshinaga S, et al. Differences in routine esophagogastroduodenoscopy between Japanese and international facilities: a questionnaire survey. Dig Endosc 2016;28(Suppl 17):16-24.

61 Gupta N, Gaddam S, Wani SB, et al. Longer inspection time is associated with increased detection of high-grade dysplasia and esophageal adenocarcinoma in Barrett's esophagus. Gastrointest Endosc 2012:76:531-8.

62 Teh JL, Tan JR, Lau LJ, et al. Longer examination time improves detection of gastric cancer during diagnostic upper gastrointestinal endoscopy. Clin Gastroenterol Hepatol 2015;13:480-7

63 Kawamura T, Wada H, Sakiyama N, et al. Examination time as a quality indicator of screening upper gastrointestinal endoscopy for asymptomatic examinees. Dig Endosc 2017;29:569-75

64 Park JM, Huo SM, Lee HH, et al. Longer observation time increases proportion of neoplasms detected by esophagogastroduodenoscopy. Gastroenterology 2017:153:460-9.

65 Daly C, Vennalaganti P, Soudagar S, et al. Randomized controlled trial of self-directed versus in-classroom teaching of narrow-band imaging for diagnosis of Barrett's esophagus-associated neoplasia. Gastrointest Endosc 2016;83:101-6.
66 Dias-Silva D, Pimentel-Nunes P, Magalhães J, et al. The learning curve for narrowband imaging in the diagnosis of precancerous gastric lesions by using web-based video. Gastrointest Endosc 2014;79:910-20.

67 Mabe K, Yao K, Nojima M, et al. An educational intervention to improve the endoscopist's ability to correctly diagnose small gastric lesions using magnifying endoscopy with narrow-band imaging. Ann Gastroentero/ 2014:27:149-55.

68 Yao K, Uedo N, Muto M, et al. Development of an e-learning system for teaching endoscopists how to diagnose early gastric cancer: basic principles for improving early detection. Gastric Cancer 2017;20(Suppl 1):28-38.

69 Yao K, Uedo N, Muto M, et al. Development of an E-learning system for the endoscopic diagnosis of early gastric cancer: an international multicenter randomized controlled trial. EBioMedicine 2016:9:140-7.

70 Zhang Q, Chan ZY, Chen CD, et al. Training in early gastric cancer diagnosis improves the detection rate of early gastric cancer - an observational study in China. Medicine 2015;94:1-8.

71 Kaltenbach T, Sano Y, Friedland S, et al. American Gastroenterological Association (AGA) Institute technology assessment on image-enhanced endoscopy. Gastroenterology 2008:134:327-40.

72 Dubuc J, Legoux J-, Winnock M, et al. Endoscopic screening for esophageal squamous-cell carcinoma in high-risk patients: a prospective study conducted in 62 French endoscopy centers. Endoscopy 2006;38:690-5.

73 Muto M, Minashi K, Yano T, et al. Early detection of superficial squamous cell carcinoma in the head and neck region and esophagus by narrow band imaging: a multicenter randomized controlled trial. J Clin Oncol 2010;28:1566-72.

74 Sharma P, Hawes RH, Bansal A, et al. Standard endoscopy with random biopsies versus narrow band imaging targeted biopsies in Barrett's oesophagus: a prospective, international, randomised controlled trial. Gut 2013:62:15-21.

75 Qumseya BJ, Wang H, Badie N, et al. Advanced imaging technologies increase detection of dysplasia and neoplasia in patients with Barrett's esophagus: a meta-analysis and systematic review. Clin Gastroenterol Hepatol 2013;11:1562-70

76 Ang TL, Pittayanon R, Lau JY, et al. A multicenter randomized comparison between high-definition white light endoscopy and narrow band imaging for detection of gastric lesions. Eur J Gastroenterol Hepatol 2015;27:1473-8.

77 Dutta AK, Sajith KG, Pulimood AB, et al. Narrow band imaging versus white light gastroscopy in detecting potentially premalignant gastric lesions: a randomized prospective crossover study. Indian J Gastroenterol 2013;32:37-42.

78 So J, Rajnakova A, Chan YH, et al. Endoscopic tri-modal imaging improves detection of gastric intestinal metaplasia among a high-risk patient population in Singapore. Dig Dis Sci 2013:58:3566-75.

79 Capelle LG, Haringsma J, de Vries AC, et al. Narrow band imaging for the detection of gastric intestinal metaplasia and dysplasia during surveillance endoscopy. Dig Dis Sci 2010;55:3442-8

80 Ang TL, Fock KM, Teo EK, et al. The diagnostic utility of narrow band imaging magnifying endoscopy in clinical practice in a population with intermediate gastric cancer risk. Eur J Gastroenterol Hepatol 2012;24:362-7.

81 Kato M, Kaise M, Yonezawa J, et al. Trimodal imaging endoscopy may improve diagnostic accuracy of early gastric neoplasia: a feasibility study. Gastrointest Endosc 2009;70:899-906.

82 Imaeda $\mathrm{H}$, Hosoe $\mathrm{N}$, Kashiwagi $\mathrm{K}$, et al. Surveillance using trimodal imaging endoscopy after endoscopic submucosal dissection for superficial gastric neoplasia. World I Gastroenterol 2014;20:16311-7.

83 Gweon TG, Park JM, Lim CH, et al. Trimodal imaging endoscopy reduces the risk of synchronous gastric neoplasia. Eur J Gastroenterol Hepatol 2015:27:215-20.

84 Shimizu Y, Omori T, Yokoyama A, et al. Endoscopic diagnosis of early squamous neoplasia of the esophagus with iodine staining: high-grade intraepithelial neoplasia turns pink within a few minutes. J Gastroenterol Hepatol 2008;23:546-50.

85 Dawsey SM, Fleischer DE, Wang GQ, et al. Mucosal iodine staining improves endoscopic visualization of squamous dysplasia and squamous cell carcinoma of the esophagus in Linxian, China. Cancer 1998:83:220-31.

86 Kuwano H, Kitamura K, Baba K, et al. Determination of the resection line in early esophageal cancer using intraoperative endoscopic examination with Lugol staining. J Surg Oncol 1992;50:149-52.

87 Inoue H. Endoscopic mucosal resection for the entire gastrointestinal mucosal lesions. Gastrointest Endosc Clin N Am 2001;11:459-78.

88 Pimentel-Nunes P, Dinis-Ribeiro M, Ponchon T, et al. Endoscopic submucosal dissection: European Society of Gastrointestinal Endoscopy (ESGE) Guideline. Endoscopy 2015;47:829-54

89 Sakai Y, Eto R, Kasanuki J, et al. Chromoendoscopy with indigo carmine dye added to acetic acid in the diagnosis of gastric neoplasia: a prospective comparative study. Gastrointest Endosc 2008:68:635-41.

90 lizuka T, Kikuchi D, Hoteya S, et al. The acetic acid + indigocarmine method in the delineation of gastric cancer. J Gastroenterol Hepatol 2008:23:1358-61.

91 Lee BE, Kim GH, Park DY, et al. Acetic acid-indigo carmine chromoendoscopy for delineating early gastric cancers: its usefulness according to histological type. $B M C$ Gastroenterol 2010;10:97. 
92 Kawahara Y, Takenaka R, Okada H, et al. Novel chromoendoscopic method using an acetic acid-indigocarmine mixture for diagnostic accuracy in delineating the margin of early gastric cancers. Dig Endosc 2009;21:14-19.

93 Zhao Z, Yin Z, Wang S, et al. Meta-analysis: the diagnostic efficacy of chromoendoscopy for early gastric cancer and premalignant gastric lesions. J Gastroenterol Hepatol 2016;31:1539-45.

94 Nagahama T, Yao K, Uedo N, et al. Delineation of the extent of early gastric cancer by magnifying narrow-band imaging and chromoendoscopy: a multicenter randomized controlled trial. Endoscopy 2018;50:566-76.

95 Nagami $Y$, Tominaga K, Machida $H$, et al. Usefulness of non-magnifying narrowband imaging in screening of early esophageal squamous cell carcinoma: a prospective comparative study using propensity score matching. Am J Gastroenterol 2014;109:845-54.

96 Pimentel-Nunes P, Dinis-Ribeiro M, Soares JB, et al. A multicenter validation of an endoscopic classification with narrow band imaging for gastric precancerous and cancerous lesions. Endoscopy 2012;44:236-46.

97 Kawai T, Yanagizawa K, Naito $S$, et al. Evaluation of gastric cancer diagnosis using new ultrathin transnasal endoscopy with narrow-band imaging: preliminary study. J Gastroenterol Hepatol 2014;29:33-6.

98 Nagai K, Ishihara R, Ishiguro S, et al. Endoscopic optical diagnosis provides high diagnostic accuracy of esophageal squamous cell carcinoma. BMC Gastroenterol 2014;14:141.

99 Mannath J, Subramanian V, Hawkey CJ, et al. Narrow band imaging for characterization of high grade dysplasia and specialized intestinal metaplasia in Barrett's esophagus: a meta-analysis. Endoscopy 2010;42:351-9.

100 Curvers WL, van den Broek FJ, Reitsma JB, et al. Systematic review of narrow-band imaging for the detection and differentiation of abnormalities in the esophagus and stomach (with video). Gastrointest Endosc 2009;69:307-17.

101 Ezoe Y, Muto M, Uedo N, et al. Magnifying narrowband imaging is more accurate than conventional white-light imaging in diagnosis of gastric mucosal cancer. Gastroenterology 2011;141:2017-25.

102 Yamada S, Doyama H, Yao K, et al. An efficient diagnostic strategy for small, depressed early gastric cancer with magnifying narrow-band imaging: a posthoc analysis of a prospective randomized controlled trial. Gastrointest Endosc 2014;79:55-63.

103 Yao K, Doyama H, Gotoda T, et al. Diagnostic performance and limitations of magnifying narrow-band imaging in screening endoscopy of early gastric cancer: a prospective multicenter feasibility study. Gastric Cancer 2014;17:669-79.
104 Zhang Q, Wang F, Chen ZY, et al. Comparison of the diagnostic efficacy of white light endoscopy and magnifying endoscopy with narrow band imaging for early gastric cancer: a meta-analysis. Gastric Cancer 2016;19:543-52.

105 Hu YY, Lian QW, Lin ZH, et al. Diagnostic performance of magnifying narrowband imaging for early gastric cancer: a meta-analysis. World J Gastroenterol 2015;21:7884-94.

106 Lv X, Wang C, Xie Y, et al. Diagnostic efficacy of magnifying endoscopy with narrowband imaging for gastric neoplasms: a meta-analysis. PLoS One 2015;10:e0123832.

107 Muto M, Yao K, Kaise M, et al. Magnifying endoscopy simple diagnostic algorithm for early gastric cancer (MESDA-G). Dig Endosc 2016;28:379-93.

108 Prueksapanich P, Pittayanon R, Rerknimitr R, et al. Value of probe-based confocal laser endomicroscopy (pCLE) and dual focus narrow-band imaging (dNBI) in diagnosing early squamous cell neoplasms in esophageal Lugol's voiding lesions. Endosc Int Open 2015;3:E281-E288.

109 Canto MI, Anandasabapathy S, Brugge W, et al. In vivo endomicroscopy improves detection of Barrett's esophagus-related neoplasia: a multicenter international randomized controlled trial (with video). Gastrointest Endosc 2014:79:211-21.

110 Sharma P, Savides TJ, Canto MI, et al. The American Society for Gastrointestinal Endoscopy PIVI (Preservation and Incorporation of Valuable Endoscopic Innovations) on imaging in Barrett's Esophagus. Gastrointest Endosc 2012;76:252-4.

111 Shaheen NJ, Falk GW, lyer PG, et al. ACG clinical guideline: diagnosis and management of barrett's esophagus. Am J Gastroenterol 2016;111:30-50.

112 Chadwick G, Groene O, Riley S, et al. Gastric cancers missed during endoscopy in England. Clin Gastroenterol Hepatol 2015;13:1264-70.

113 Beg S, Ragunath K, Wyman A, et al. Quality standards in upper gastrointestinal endoscopy: a position statement of the British Society of Gastroenterology (BSG) and Association of Upper Gastrointestinal Surgeons of Great Britain and Ireland (AUGIS). Gut 2017;66:1886-99.

114 Evans JA, Early DS, Fukami N, et al. The role of endoscopy in Barrett's esophagus and other premalignant conditions of the esophagus. Gastrointest Endosc 2012;76:1087-94

115 Weusten B, Bisschops R, Coron E, et al. Endoscopic management of Barrett's esophagus: European Society of Gastrointestinal Endoscopy (ESGE) Position Statement. Endoscopy 2017:49:191-8.

116 Evans JA, Chandrasekhara V, Chathadi KV, et al. The role of endoscopy in the management of premalignant and malignant conditions of the stomach. Gastrointest Endosc 2015;82:1-8. 